\title{
NOTAS SOBRE A FORMAÇÃO DO ESTADO \\ CAPITALISTA NO BRASIL: NACIONALIZAÇÃO \\ E ESPECIALIZAÇÃO (1930-1964)
}

\author{
Maria Letícia Corrêa* \\ leticiacorrea@globo.com
}

RESUMO: Este artigo propõe uma contribuição para o conhecimento do processo histórico da formação do capitalismo e da constituição do Estado, a partir da análise de aspectos institucionais e da composição de setores da burocracia técnica, desde o primeiro governo de Getúlio Vargas (1930-1945), até o advento do regime militar (1964). A partir da análise feita, realiza-se uma discussão sobre noções presentes na historiografia associada à tese da modernização autoritária, por meio do questionamento da atuação dos quadros técnicos e/ou burocráticos nas diversas agências.

Palavras-CHAVE: Desenvolvimento capitalista, formação do Estado, burocracias.

A história diz respeito ao capital e à coerção.

(Charles Tilly)

Neste trabalho apresento algumas proposições para a análise do processo histórico de formação do capitalismo no Brasil, com especial ênfase na investigação de determinados aspectos da constituição do Estado, no período iniciado com o advento da chamada "Era Vargas", até a implantação do regime militar, em 1964.

Para a consecução desse objetivo, será necessário, num primeiro momento, retomar a avaliação do conjunto de reflexões que, nas ciências sociais e na historiografia brasileira e latino-americana, pretenderam discutir em caráter pioneiro as relações entre Estado e economia, abrangendo a análise das políticas de governo e sua repercussão sobre a economia nos diferentes países, na transição para o capitalismo, e o papel dos Estados nacionais na promoção do desenvolvimento econômico. $\mathrm{O}$ debate entre os

\footnotetext{
* Professora de História do Brasil na Universidade do Estado do Rio de Janeiro.
} 
autores que empreenderam essas reflexões resultou na proposição de uma periodização do processo de formação do capitalismo no Brasil, que é tomada como base neste trabalho em que se sugere sua correspondência com o processo específico de formação do Estado capitalista.

A segunda ordem de questões refere-se ao estudo do processo de constituição do aparato administrativo-burocrático nas etapas de nacionalização e especialização, quando o Estado capitalista brasileiro veio a adotar uma gama altamente expandida de atividades de distribuição, regulamentação, compensação e justiça, para além das tarefas tradicionais de operação do aparelho fiscal e do aperfeiçoamento das forças militares profissionais (Tilly, 1996, p. 79). ${ }^{1}$ Nessa perspectiva teórica, associava-se diretamente às atividades de distribuição, regulamentação e compensação, desde a década de 1930, o conjunto de iniciativas de intervenção, regulação e planejamento econômico.

Esse estudo pauta-se pelo pressuposto de que, no processo de expansão do Estado capitalista brasileiro, a criação dos diferentes órgãos guardava uma correspondência, enquanto materialidade institucional, ${ }^{2} \mathrm{com}$ a manifestação dos conflitos, estratégias e alianças entre classes e frações de classes, levando em consideração que as lutas econômicas que caracterizam a formação do capitalismo atravessam também as estruturas do próprio Estado, constituindo formas cristalizadas de relações e conflitos sociais (DRAIBE, 1985, p. 49). Desse modo, se o período posterior à Revolução de 1930 foi traduzido, no aparelho estatal, pela crescente diversificação e heterogeneidade das instâncias político-administrativas, essa mesma etapa do processo de formação do Estado marcou uma nova modalidade de representação dos interesses de classes e frações de classes nos órgãos relacionados à formulação e à execução das diversas políticas setoriais e também no conjunto de atos legislativos e códigos reguladores.

Esta análise busca abarcar um intervalo temporal bastante extenso, desde os anos 30 até o advento do regime militar, partindo de uma perspectiva teórica que busca também estabelecer uma continuidade entre as diferentes etapas da periodização do processo de constituição do Estado, na história do Brasil republicano, pela comparação, por exemplo, dos padrões vigentes nos períodos de fechamento do regime, como o Estado Novo, com a etapa constitucional até o advento do regime militar, em 1964. A percepção dessa continuidade nos leva a sugerir a persistência de uma tendência autoritária e concentradora do poder em todo o período, resultante dos padrões de intervenção econômica, como conjunto de políticas públicas. Não por acaso, no mesmo período, pelo menos desde a criação da Escola Superior 
de Guerra em 1949, avança a formulação de uma doutrina autoritária ligando os dois pólos do desenvolvimento econômico e da segurança nacional, cujos principais enunciados foram propostos, ainda que não em caráter exclusivo, por oficiais das forças armadas.

\section{ESTADO E DESENVOLVIMENTO ECONÔMICO: UMA PERIODIZAÇÃO DA HISTÓRIA DO CAPITALISMO NO BRASIL}

A ruptura imposta pelo advento do primeiro governo de Getúlio Vargas, com relação à República Velha, é em geral avaliada como um marco fundamental para a história econômica brasileira (MENDONÇA, 1985; ABREU, 1989; BielSCHOWSKY, 1995; Gremaud et al., 1997; FioRI, 1999). O fenômeno do rápido crescimento da indústria no pós-1930 fora percebido por contemporâneos, como Roberto Simonsen, que o apontou na obra pioneira A evolução industrial do Brasil (SimONSEN, [1939]1972; MAZA, 2004).

A controvérsia na qual se inscreveu o debate sobre o desenvolvimento econômico no Brasil foi a da elaboração da teoria do subdesenvolvimento, consolidada em virtude dos argumentos e da publicação dos textos fundamentais de Raul Prebisch e da Comissão Econômica para a América Latina (Cepal), a partir do final dos anos 40 (BieLsCHOWSKY, 1995, p. 11-15). A contribuição desses autores, expressa na formulação da tese da industrialização por substituição de importações, tem sido avaliada como um dos marcos do estruturalismo latino-americano, que, segundo José Luís Fiori, "produziu uma verdadeira revolução teórica na discussão do problema do subdesenvolvimento" (FIORI, 1999, p. 28).

Prebisch (1949) e Celso Furtado (1959) propuseram, nesse contexto, todo um novo programa de pesquisa partindo do sistema econômico mundial e explicando o atraso econômico pela difusão desigual do progresso tecnológico, induzida, por sua vez, pelo funcionamento hierárquico $\mathrm{e}$ assimétrico das relações entre economias nacionais que se haviam integrado de maneira diferenciada aos centros da economia mundial. Tais autores foram os responsáveis pela proposição de uma "visão estrutural e histórica do capitalismo, entendido como um sistema econômico em expansão a partir da revolução industrial européia e que foi incorporando sucessivas periferias especializadas e articuladas com base nos mercados e investimentos das economias centrais" (FIORI, 1999, p. 28-29).

A apresentação de forma sistemática dos eventos e da política econômica do pós-1930, para a análise dos fatores do crescimento da produção industrial brasileira, foi realizada por Celso Furtado em Formação econô- 
mica do Brasil (1959). O quadro sistematizado por Furtado, descrevendo o já mencionado processo de industrialização por substituição de importações, seria exposto em sua formulação mais acabada por Maria da Conceição Tavares em Da substituição de importações ao capitalismo financeiro ([1963]1972), ensaio no qual foi elaborada a sua generalização para o conjunto das economias latino-americanas.

Como é bastante conhecido, Furtado pretendeu dar conta da transformação pela qual a produção voltada para o mercado interno, em especial a manufatureira, passou a constituir, depois de 1930, o centro dinâmico da economia; isto é, buscou oferecer uma explicação para o processo histórico a partir do qual a produção doméstica passava a determinar a taxa de crescimento e o nível do produto, da renda e do emprego, uma vez que, até a República Velha, o centro dinâmico corresponderia ao setor exportador.

A mudança realizada em 1929-1930 relacionou-se com um conjunto de efeitos de diferentes ordens que inviabilizaram a continuidade da política de defesa do café nos moldes em que vinha sendo realizada desde 1906, quando se deu o início da implementação do programa de valorização do Convênio de Taubaté. O que então ocorreu foi em parte decorrência de uma seqüência de safras elevadas, que haviam levado à acumulação de grandes estoques e ampliado as necessidades de financiamento de forma significativa. Além disso, a crise mundial iniciada com a queda da Bolsa de Nova York, atingindo o mercado financeiro internacional, impossibilitou a obtenção de recursos externos sob a forma de empréstimos, e a depressão econômica nos países importadores de café ampliou a pressão que a superprodução exercia sobre os preços no mercado internacional. Esse conjunto de efeitos determinou a queda dos preços internacionais do café e, em conseqüência, a redução da receita das exportações brasileiras e da capacidade de importar do país.

Após a crise de 1929, portanto, o governo federal viu-se forçado a retomar a política de defesa do café sob novas condições. Na impossibilidade dos empréstimos externos, o financiamento dessa compra teria de ser feito com recursos internos obtidos pela tributação do produto exportado e por meio do crédito ou emissão de moeda. Como parte dos estoques formados não era passivel de venda a médio prazo, determinou-se a queima de estoques com o objetivo de reduzir a pressão sobre o mercado.

A conjuntura do imediato pós-1930, segundo essa análise, teve resultados importantes para a diversificação da economia brasileira no rumo da industrialização. Uma vez que a desvalorização da moeda nacional se fez em proporção maior que o aumento dos preços internos, a produção naci- 
onal se viu protegida diante do produto importado, cujo preço relativo aumentara frente ao produto nacional. Por outro lado, diante da brutal queda do preço do café, a produção destinada ao mercado interno (principalmente as manufaturas) tornou-se mais atrativa em relação aos produtos exportáveis. O crescimento da produção industrial no período teria sido sustentado em primeiro lugar pela capacidade ociosa existente e, posteriormente, por meio da importação a baixo custo de máquinas usadas dos Estados Unidos e da Europa. Além disso, a produção de bens de capital passou a ser feita em parte internamente, uma vez que aquela conjuntura se configurava como um ambiente inédito para uma economia exportadora, isto é, pela primeira vez conjugava-se demanda de bens de capital com restrição da capacidade de importar. As exportações ainda teriam um papel importante, pois forneciam as divisas necessárias para a importação de máquinas e equipamentos, uma vez que a produção de bens de capital ainda era limitada no Brasil. O regime cambial e o nível da taxa de câmbio, em particular, ganharam importância central na definição da política de desenvolvimento, a partir dessa etapa (GREMAUD et al., 1997, p. 108-109).

A tese de Furtado foi qualificada em função de trabalhos posteriores, que indicaram a coincidência que por vezes se verificava entre os interesses do café e os da indústria na gestão da política econômica, desde a República Velha, bem como a diversificação anterior dos interesses da burguesia cafeeira, que ainda naquele período teria investido na infra-estrutura de exportação e na indústria substitutiva de importações.

Na direção dessa interpretação, destaca-se a obra intitulada $A$ industrialização de São Paulo, 1880-1945, de Warren Dean (1971). Baseado na leitura de declarações governamentais de caráter "antiprotecionista" e no argumento de que a política comercial do governo provisório de Vargas não teria acarretado o aumento da proteção à indústria, Dean sugeriu que as políticas do novo regime não teriam favorecido esse setor, em oposição à cafeicultura. Para o mesmo autor, a década de 1930 não teria constituído um período crucial para a aceleração do processo de industrialização brasileira, uma vez que a produção industrial havia crescido mais significativamente na década anterior.

Outras interpretações buscaram mostrar que as medidas anti-crise adotadas pelo governo brasileiro no imediato pós-1930 teriam tido um sentido antes tradicional e ortodoxo, prejudicando a recuperação da atividade econômica, e que, dessa forma, o governo da Revolução de 1930 não teria defendido adequadamente os interesses da indústria. Destacam-se, no quadro de revisões da tese clássica de Celso Furtado, a interpretação apresenta- 
da por Carlos Manuel Pelaez em História da industrialização brasileira (1972) e o trabalho intitulado Políticas de governo e crescimento da economia brasileira, de Annibal Villanova Villela e Wilson Suzigan (1975). Em particular, quanto ao café, Pelaez sugeriu que os gastos com a compra de produção excedente haviam sido financiados por taxação das exportações do produto e não pela expansão do crédito, o que conflita com evidências apresentadas pelo próprio autor para o período posterior a 1931, as quais demonstram que um terço dos gastos com a compra do café foi custeado com créditos do governo no intervalo até 1934 (ABREU, 1989, p. 81).

Segundo Marcelo de Paiva Abreu, essa tentativa de revisão da interpretação clássica do significado dos anos 30 teria deixado de considerar que, para além da política específica de defesa do café, o governo provisório de Getúlio Vargas aumentara de fato a proteção à indústria por meio de um conjunto de medidas que incluiu também o aumento de impostos específicos, a regulação do consumo compulsório de matérias-primas e a proibição da importação de equipamentos para determinadas indústrias caracterizadas por sua capacidade ociosa. Além disso, ainda segundo Abreu, a proteção tarifária teria aumentado até 1934 , não se tendo praticado, ao longo dos anos 30, tarifas inferiores às vigentes em 1928 (ABREU, 1989, p. 80-81).

A tese da industrialização por substituição de importações, proposta por Furtado para o caso brasileiro, foi consolidada, como indicado acima, com a contribuição de Maria da Conceição Tavares no já citado $D a$ substituição de importações ao capitalismo financeiro, ensaio no qual a autora ampliou essa consideração como proposta de interpretação para o desenvolvimento capitalista do conjunto das economias latino-americanas.

Tavares caracterizou as economias primário-exportadoras latinoamericanas pelo alto peso do setor externo na composição da renda nacional e pelo fato de as exportações serem a única componente autônoma do crescimento da renda nesses países. Dessa feita, a atividade do setor exportador teria sido suficiente para induzir a urbanização e o surgimento de algumas indústrias de bens de consumo (tecidos, calçados, vestuário, móveis). No entanto, a indústria e o setor agrícola de subsistência não eram capazes de dar o dinamismo próprio à atividade econômica interna, isto é, tinham seu ritmo determinado pelo do setor exportador.

A crise prolongada dos anos 30 teria constituído, para a América Latina, o ponto de ruptura do funcionamento do modelo primário-exportador, com a passagem para um modelo de desenvolvimento "voltado para dentro". Como na análise de Furtado, Tavares enfatizou que a profundidade da crise dos anos 30 conduzira a maior parte dos governos latino-america- 
nos a tomar medidas de controle do comércio externo, das taxas de câmbio e de compra de excedentes exportáveis, com o que se evitou o declínio acentuado da renda interna. Também como em Furtado, na interpretação proposta pela autora a manutenção do nível de demanda interna com redução da capacidade de importar e o efeito cambial decorrente, levando ao aumento dos preços relativos das importações, estimularam a produção interna substitutiva das importações.

A dinâmica do processo de industrialização na América Latina respondeu às sucessivas situações em que o desequilíbrio externo se reproduzia como conseqüência da própria substituição prévia de importações, pois esta exigia a importação de máquinas, bens intermediários etc. Segundo essa análise, o processo de substituição de importações se iniciava pelos bens de consumo finais, cuja demanda aparece de forma imediata e cuja produção é tecnologicamente mais simples, além de exigirem menor volume de recursos para sua implantação. $O$ estabelecimento de indústrias para produzir internamente o que antes era importado, por um lado aumentava o mercado interno pelo crescimento da renda derivada do investimento industrial e também porque agora eram menores as restrições de acesso a esses produtos (do que quando eram importados). Por outro lado, a produção interna de bens exigia a importação de matérias-primas e outros insumos que anteriormente não constavam da pauta de importaçóes, exercendo pressão sobre disponibilidade de divisas. ${ }^{3}$

A revisão e a crítica da tese da estagnação das economias latino-americanas como característica do processo de industrialização por substituição de importações seriam elaboradas pela própria Maria da Conceição Tavares em texto posterior, escrito em co-autoria com José Serra e intitulado Mais além da estagnação (1970). Nesse ensaio, a ruptura com a interpretação anterior está no fato de que o estrangulamento externo deixava de ter o peso explicativo que assumia naquela tese, a industrialização não aparecendo mais como resposta ao desequilíbrio externo, e sim como fruto de um processo de acumulação de capital que, ao longo do tempo, teria assumido diferentes padrões.

Nessa nova perspectiva, a década de 1930 continuava a representar um momento de ruptura, pois, superada a crise, a acumulação industrial e a renda fiscal do governo se teriam desvinculado da acumulação cafeeira, estando daí em diante subordinadas ao desenvolvimento urbano-industrial. A diferença entre esse novo argumento e o do deslocamento do centro dinâmico é que na nova interpretação o padrão de acumulação estabelecido na década de 1930 não poderia ser entendido como mero reflexo dos 
problemas externos, mesmo que o período fosse formalmente caracterizado como de substituição de importações.

Essa revisão propõe o conceito de industrialização restringida, etapa que se estende de 1933 a 1955 e que surgiu como resposta a mudanças no padrão de acumulação de capital, as quais não correspondem, somente, às contradições decorrentes do estrangulamento externo, pressupondose, para a adoção do novo conceito, o prévio desenvolvimento do capital industrial. Além disso, ao período da industrialização restringida teria correspondido uma nova dinâmica de crescimento, não mais comandada pelo capital cafeeiro e resultado de dois fatores contraditórios. Se, por um lado, o processo de expansão industrial comandava a acumulação de capital, o desenvolvimento das forças produtivas e a acumulação urbana eram, entretanto, insuficientes para garantir a implantação da indústria de base. $\mathrm{O}$ crescimento do setor de bens de produção durante a industrialização restringida, mesmo que em proporção maior do que o do conjunto da indústria, ainda não era dominante e permanecia incapaz de atender à demanda corrente. Por esse motivo, a expansão econômica permaneceria dependente do setor de bens de consumo assalariado, estabelecido na etapa anterior e protegido pela redução da capacidade de importar (Gremaud et al., 1997, p. 31-44).

Essa interpretação do desenvolvimento industrial brasileiro propôs uma nova periodização, diferente daquela contida na tese da industrialização por substituição de importações. O momento de ruptura de padrão passou a ser situado na segunda metade dos anos 50, com a implantação da indústria de bens de produção e bens de consumo duráveis, a partir de quando o movimento da economia brasileira poderia ser entendido com base nas relações entre os setores de produção. ${ }^{4}$

A releitura do pensamento estruturalista, bem como de suas estratégias econômicas, resultando na leitura do capitalismo tardio, completou-se no ensaio Acumulação de capital e industrialização no Brasil, de Maria da Conceição Tavares (1974), e em Capitalismo tardio, de João Manuel Cardoso de Mello (1982). O objeto central dessas análises tornara-se agora predominantemente endógeno, isto é, a questão da internalização dos mecanismos de acumulação de capital ganhou destaque em face das relações de dependência externa, que constituíram a tônica dos trabalhos da década anterior. A viabilidade do capitalismo brasileiro já não estava em discussão, mas tinha que ser repensada como a história de um certo tipo de capitalismo tardio, definido a partir de uma dupla determinação, isto é, o seu passado imediato de economia exportadora e escravista e o momento de sua inser- 
ção internacional num capitalismo monopolista em escala mundial. O capitalismo brasileiro desenvolvera-se sem contar com um departamento produtor de bens de produção e bloqueado por obstáculos financeiros e tecnológicos que o mantiveram restringido até meados da década de 1950, quando teria sido desbloqueado pela ação conjunta do Estado e da grande empresa oligopolista internacional. ${ }^{5}$

O conceito de industrialização restringida foi desenvolvido especialmente na obra de João Manoel Cardoso de Mello, como correspondendo à etapa do desenvolvimento capitalista dependente caracterizada por uma ambigüidade, qual seja, a da necessidade e da dependência da transferência, para o setor industrial, de recursos e capitais gerados pela agroexportação.

Ao lado da tradição estruturalista, haviam se desenvolvido, também, ainda nos anos 60, as várias teorias da dependência. Dentre as diversas vertentes integrantes da "escola" da dependência, destacou-se, em primeiro lugar, a tese do "desenvolvimento do subdesenvolvimento", elaborada por André Gunder Frank, a qual caracterizava o subdesenvolvimento como resultado de um certo tipo de desenvolvimento capitalista, condicionado pelo sistema internacional hierarquizado, em que os países avançados exploravam os menos desenvolvidos, transferindo parte do seu excedente, e pela aliança destes com as "burguesias compradoras", responsáveis pelo consumo de luxo. Nessa interpretação, o capitalismo em sua fase monopolista bloqueava o desenvolvimento industrial dos países atrasados.

As demais vertentes da teoria da dependência, identificadas nos trabalhos de Osvaldo Sunkel, Aníbal Pinto, Fernando Henrique Cardoso e Enzo Faletto, entretanto, passavam a deixar de lado a caracterização da dependência como um fator explicativo do atraso, enfatizando a necessidade da análise do comportamento das estruturas, processos e interesses internos a cada país, isto é, da dimensão propriamente política do desenvolvimento capitalista.

Essa concepção tornava imperativa a realização de estudos visando à identificação dos conjuntos de estratégias e alianças entre classes e frações de classes latino-americanas, internamente, e sua inserção no quadro da economia capitalista mundial, nos termos da expansão imperialista, a partir do século XIX. Suas análises reinstauraram, como questão nuclear para o entendimento da transição capitalista nesses países, portanto, o estudo dos processos históricos de constituição dos Estados nacionais. 
CONSTITUIÇÃO DO ESTAdO CAPITALISTA BRASILEIRO: POLITIZAÇÃO DOS SETORES TÉCNICOS

Nos estudos que se debruçaram diretamente sobre a formação dos Estados nacionais latino-americanos a partir da década de 1970 foi determinante a influência das análises histórico-comparativas sobre trajetórias e padrões de industrialização e modernização política, como aquelas produzidas por Alexander Gerschenkron (1962), Barrington Moore Jr ([1962]1983) e Perry Anderson ([1974]1985), que buscavam dar conta da multiplicidade dos caminhos percorridos pela industrialização, modernização e formação dos Estados. A leitura desses autores contribuiu para reforçar ainda mais as dúvidas quanto às previsões e perspectivas evolucionistas e lineares sobre a expansão do capitalismo e a transformação institucional das sociedades tradicionais, no sentido da democratização.

Nesse contexto, a contribuição mais importante para o debate teórico latino-americano teria vindo da identificação de um segundo paradigma ou via tardia de industrialização e modernização conservadora, ou autoritária - semelhante ao que Engels e Lênin tinham identificado para a Alemanha do século XIX como via "pelo alto" ou "prussiana" -, reunindo burguesias frágeis e internacionalizadas com burocracias estatais fortes e militarizadas, num quadro de uma economia basicamente rural, de lenta mercantilização e repressão de mão-de-obra, em que a industrialização acelerada servida concomitantemente aos interesses militares e da potência estatal (FIORI, 1999, p. 29).

Essa nova abordagem, cuja expressão pode ser encontrada em $A$ Revolução Burguesa no Brasil (1975), de Florestan Fernandes, teve o mérito de denunciar como falso o suposto caráter progressista ou mesmo nacional das frações de classes dominantes locais, e também o de questionar o caráter democrático de alianças por vezes classificadas como "populistas", apoiadas pelos partidos comunistas latino-americanos desde os anos 30. Articulava-se, por esse motivo, uma dura crítica à estratégia da revolução democrático-burguesa proposta por aquelas lideranças, que se manteve em grande parte inalterada até o início do ciclo dos regimes militares no continente.

No Brasil, a historiografia sobre as relações entre Estado e economia - incluindo-se, nesse quadro, as abordagens empreendidas no bojo da formulação da chamada "teoria da dependência" e também os estudos sobre as políticas de governo e sua repercussão sobre a economia dos Estados latino-americanos na transição para o capitalismo - ressaltou o papel dos Estados nacionais na promoção do desenvolvimento econômico. Na revisão da 
economia política da Cepal, como indicado acima, apontava-se a necessidade de abordar as estratégias empreendidas pelas frações das classes dominantes, internamente, e sua inserção no quadro do imperialismo, para uma melhor compreensão do desempenho das diferentes economias.

O processo histórico de constituição do Estado capitalista brasileiro foi analisado por um conjunto de autores que visaram abarcar o aprofundamento do seu caráter autoritário, desde 1930, e a montagem da estrutura política corporativa no período chamado populista (CARDOSO, 1975; WeFfort, 1984; JaGuaribe, 1985; SOla, 1993; Gomes, 1996). ${ }^{6}$

Dentre os estudos pioneiros que buscaram analisar o processo de modernização econômica no Brasil, com ênfase no estudo do aparato administrativo-burocrático constituído a partir da chamada "Era Vargas", com a constituição dos diversos órgãos relacionados à formulação e à execução de políticas setoriais, destacou-se Pouvoir et dévéloppement économique: formation et évolution des structures politiques au Brésil (1976), de Luciano Martins, que, por meio do emprego do conceito de modernização autoritária, apontou o papel de segmentos burocráticos, na avaliação do autor dotados de autonomia e poder decisório para realizar o planejamento do desenvolvimento capitalista segundo critérios considerados universalistas.

Nesse contexto, a complexidade das estruturas do Estado brasileiro no pós-1930 materializou-se nos órgãos relacionados à formulação e à execução de políticas setoriais e nos órgãos normatizadores então criados, bem como em atos legislativos e códigos reguladores. Um exemplo da nova modalidade de representação de interesses, através das lideranças industriais, foi descrito no trabalho de Eli Diniz, que se refere em especial à atuação do Conselho Federal de Comércio Exterior e dos diversos órgãos de supervisão econômica criados durante o Estado Novo (DinIZ, 1978, p. 148).

Diniz apontou a crescente participação dos quadros técnicos nas discussões levadas a efeito nessas agências, ressaltando o caráter por vezes mais elaborado e radical das posições assumidas por esses técnicos, quando confrontadas com as lideranças industriais. Registra-se, como exemplo, que os técnicos teriam sido responsáveis pelo aprofundamento da análise acerca das conseqüências da falta de diretrizes governamentais sobre a questão do capital estrangeiro e pela apresentação de denúncias sobre irregularidades praticadas por empresas estrangeiras estabelecidas no país, tendo assumido por vezes uma postura intransigente nessas matérias. Também teria se manifestado, entre os quadros de técnicos das diversas agências, a defesa de uma posição mais radical em relação ao intervencionismo estatal e à regulamentação ampla dos setores industriais, pelo papel centralizador do Estado. 
Embora se deva ressaltar a qualificação apresentada pela mesma autora, relativa à ausência de uma visão homogênea por parte de empresários ou técnicos, durante o Estado Novo, nenhum desses grupos indicaram a necessidade da formulação de um projeto global de crescimento industrial para o país, mesmo quando considerado o aspecto da empresa estrangeira (DinIz, 1978, p. 194-195).

Em trabalho posterior, Diniz apontou novamente a passagem da década de 1930 como período marcado pelo esvaziamento do poder dos grupos interessados em manter a preponderância do setor externo no conjunto da economia e pela ascensão dos interesses ligados à produção para o mercado interno. Nesse processo de transição, administrado pelo primeiro governo de Vargas, ocorreu o ingresso dos novos atores - como as elites industriais emergentes - sem que as antigas elites tenham sido desalojadas.

A reforma do Estado iniciada durante o governo constitucional, através das medidas voltadas para a desarticulação do Estado oligárquico, não eliminou por completo o padrão clientelístico vigente na etapa anterior, tendo resultado desse processo de transição "um sistema estatal híbrido, marcado pela interpenetração entre os aspectos do modelo racional legal e a dinâmica clientelista". Nesse quadro, foi o corporativismo do pós-1930 que possibilitou a incorporação política de empresários e trabalhadores urbanos sob a tutela do Estado, manifestando-se na montagem da "rede de organização de representação de interesses, regulados e controlados pelo poder público". Foi nesse contexto que os conselhos técnicos se tornaram as peças básicas da nova engenharia institucional (DINIZ, 1999, p. 25-26).

$\mathrm{O}$ formato institucional que resultou dessa tendência foi seguido por um novo modo de definição e implementação de políticas públicas, deslocado para instâncias enclausuradas na alta burocracia e protegidas de interferências externas, com o que se buscava eliminar formas de manifestação autônoma de interesses. A nacionalização e a burocratização do processo decisório apresentam-se, portanto, na análise de Diniz, como duas faces do mesmo processo mais geral de centralização e de concentração do poder do Estado, o que é complementado, ainda, com a enunciação da ideologia autoritária e dos valores legitimadores do novo modelo, pela afirmação do papel integrador e regenerador do Estado forte e da supremacia da técnica em relação à política, no sentido estrito, quando a última passa a ser vista como fonte de distorção e fator de irracionalidade na condução dos negócios públicos.

Segundo Sônia Draibe, a expansão da burocracia e o aumento da complexidade do Estado brasileiro a partir da "Era Vargas" criaram as condições para a elaboração de políticas de caráter nacional, concebidas 
doravante como de "interesse geral", acima dos conflitos de classes. Nessa interpretação, a política do governo era definida a partir da hierarquização das prioridades e interesses representados nas diferentes agências do Estado, configurando-se o espaço de ação da sua "autonomia relativa" de acordo com as diversas composições da aliança de poder, sendo o exercício da função legislativa do Poder Executivo apenas uma de suas manifestações (Draibe, 1985, p. 80-81).

Os traços autoritários que caracterizaram a reordenação institucional do Estado brasileiro foram acentuados desde o Estado Novo até os anos 50 - estabelecendo-se portanto uma continuidade entre a primeira etapa de fechamento do regime e a nova etapa constitucional -, por meio do processo de politização da economia e da montagem das diversas agências centralizadas e nacionais, o que tornava possível uma modalidade de intervenção limitada, em que o caráter parcial das diversas iniciativas de planejamento e a superposição de órgãos e funções no Estado decorriam do estilo de canalização das demandas via representação direta, sem que se fizesse valer o sistema partidário, por exemplo (Draibe, 1985, p. 233). Na década de 1950 a ação do Estado foi redefinida pela sua transformação em investidor produtivo, para o que sua capacidade de financiamento foi garantida pela ampliação da estrutura tributária e pela criação de fundos específicos e vinculados - como o do setor de óleos e combustíveis e o de eletrificação e também por intermédio da opção pela empresa pública ou de economia mista. $^{\text {? }}$

A ampliação das funções de regulamentação pelo Estado, no pós1930 , colocou pela primeira vez a burocracia técnica no centro dos conflitos e debates que tinham lugar nos diversos órgãos de decisão econômica, tornando "mais enfática a dimensão política das resoluções técnicas". O conhecimento especializado e o domínio técnico sobre as decisões "capacitam-no (o técnico) a operar como pivô nos sistemas de forças e nas alianças entre grupos de interesses e nas articulações interburocráticas em torno de alvos comuns", o que seria um traço característico do capitalismo tardio (Draibe, 1985, p. 52-53).

A tendência à formação de uma burocracia técnica no Estado Brasileiro, integrada por engenheiros, economistas e setores das forças armadas, tem sido relacionada, na historiografia, à elaboração do projeto de industrialização do país, segundo análises que adotam como ponto de partida o primeiro governo de Vargas, tido como um marco no processo de constituição e organização das agências especializadas nos diversos setores como o do petróleo, comércio exterior e siderurgia (MARTINS, 1976; WIRTH, 1973; 
Diniz, 1978; Draibe, 1985). São tomados como indicativos dessa ruptura eventos como a organização do Departamento Administrativo do Serviço Público (Dasp), em 1938, e da Fundação Getúlio Vargas, em 1944, a fixação de critérios universalizados para o recrutamento do funcionalismo público e a instituição dos concursos, o que permitiria substituir mecanismos predominantemente políticos e/ou clientelísticos na indicação dos quadros por critérios meritocráticos, entre outras mudanças importantes.

Nesse contexto, o papel dos diversos quadros técnicos foi associado à apresentação dos projetos de classe, no debate entre as alternativas para o desenvolvimento brasileiro (DRAIBE, 1985), tendo sido notada a ampliação do campo de atuação desses profissionais em função de sua participação nos setores de obras públicas e nas empresas estatais. Essa atuação se acentuou a partir de meados do século XX, em decorrência da expansão do mercado interno e da industrialização (DIAS, 1994, p. 17).

O caráter descentralizado das iniciativas de intervenção econômica no período anterior ao governo de Juscelino Kubitschek (1956-1961), que implicou a concomitância e a multiplicação das ações de políticas e planejamento, não impediu, entretanto, que um grupo bastante concentrado de técnicos, integrado por engenheiros, economistas e oficiais das forças armadas, viesse a consolidar a experiência comum necessária à elaboração de uma abordagem mais completa do conjunto dos problemas que afetavam o desenvolvimento econômico brasileiro, exatamente em função das numerosas oportunidades oferecidas à sua participação em órgãos como o Conselho Federal de Comércio Exterior, o Conselho Técnico de Economia e Finanças, o Conselho Nacional de Economia, o Banco Nacional de Desenvolvimento Econômico (desde 1952) e o Conselho do Desenvolvimento (desde 1956), sem falar no conjunto de políticas conduzidas a partir dos setores mais "tradicionais" da burocracia, no âmbito dos ministérios da Fazenda e do Trabalho, Indústria e Comércio.

Teve relevância, também, a experiência de análise técnica e proposição de políticas de planejamento das equipes reunidas a partir das missões de colaboração norte-americana, como a Missão Cooke (1942), a Missão Abbink (1948) e a Comissão Mista Brasil-Estados Unidos (1952), revelando-se, nesses casos, a conformidade do processo de formação do Estado às condições impostas pelas relações externas, no quadro da Guerra Fria (Fico, 2000, p. 172-175; Tilly, 1996, p. 179-180). Cabe notar, também, uma correspondência entre as análises e propostas ensaiadas nessas missões e o conjunto de medidas mais tarde implementado a partir do Programa de Metas do governo Kubitschek, na segunda metade da década de 1950 (LAFER, 2002). 
Segundo Lourdes Sola, foi a partir da Missão Cooke que se consolidou no Estado brasileiro um processo em que o saber e a experiência técnica foram sendo gradualmente acumulados pelos agentes envolvidos nesse tipo de iniciativa - os técnicos e dirigentes reunidos nos órgãos econômicos da administração direta ou em comissões ad hoc -, o que redundava em uma consciência progressivamente mais apurada e realista dos fatores que restringiam a gestão da economia brasileira, fosse nos moldes propostos pelos liberais - como nas iniciativas de política econômica praticadas nos primeiros anos do governo de Dutra e nas missões de colaboração mistas -, fosse nos projetos dos técnicos "nacionalistas" (SolA, 1998, p. 80-81). Foi também a partir dessas iniciativas que se consolidou um diagnóstico, por parte dos técnicos, segundo o qual as restrições ao desenvolvimento brasileiro decorriam tanto dos obstáculos do quadro político nacional - como, por exemplo, as dificuldades para o estabelecimento de acordos no Congresso Nacional com vistas à implementação das diversas propostas e as divergências existentes dentro dos próprios órgãos do Executivo federal -, como também das mudanças nas estratégias e prioridades do governo dos Estados Unidos em relação ao Brasil e à América Latina, desde o final da Segunda Guerra Mundial.

Por sua vez, o levantamento dos quadros de integrantes dessas diversas iniciativas de planejamento aponta para o fato de que seu recrutamento se deu dentro de um grupo bastante concentrado de técnicos, portadores já naquela etapa de uma consolidada experiência nos setores público e privado, o que reforçava ainda mais o fortalecimento e a centralidade do seu papel enquanto formuladores, no governo federal, das políticas de desenvolvimento e industrialização.

A Missão Cooke fora criada em 1942, por solicitação direta de Vargas ao governo dos Estados Unidos, após a decisão sobre a participação brasileira na Segunda Guerra Mundial, ao lado dos aliados. Integrada por técnicos norteamericanos e técnicos e empresários brasileiros, seu trabalho, divulgado pelo governo dos Estados Unidos em 1948, foi orientado pelos objetivos básicos de desenvolver estudos e propor medidas com o objetivo de aumentar a produção brasileira de produtos essenciais, antes importados, adaptar as indústrias brasileiras a tecnologias mais avançadas, aperfeiçoar os meios de transporte e canalizar a poupança interna para atividades do setor industrial. Os técnicos da Missão Cooke realizaram estudos sobre temas variados como transportes, combustiveis, petróleo, energia, indústria têxtil, mineração, metalurgia e indústria química e, dado o amplo escopo dos estudos realizados, seu trabalho foi avaliado como um dos primeiros esforços para a elaboração de um diagnóstico geral da economia no país. 
A Missão Abbink, ou Comissão Brasileiro-Americana de Estudos Econômicos, organizada em setembro de 1948, no governo Dutra (19461950), era composta, como a antecessora, por um grupo de técnicos norteamericanos, liderados pelo economista John Abbink, sendo a seção brasileira chefiada pelo economista Otávio Gouveia de Bulhões e integrada por Valentim Bouças, Mário Bittencourt Sampaio, Aníbal Alves Bastos, general Anápio Gomes e Afonso Almiro R. Costa. Contava, ainda, com a colaboração de técnicos como Glycon de Paiva Teixeira, Rômulo Almeida e Ari Frederico Torres, configurando um núcleo de técnicos que confirmariam uma atuação de destaque nas áreas de planejamento do governo federal nas décadas de 1950 e $1960 .^{8}$

Os resultados do trabalho dessa segunda missão, com escopo também bastante abrangente e contendo análises sobre os diversos segmentos econômicos e as condições necessárias para o desenvolvimento, considerando a participação do Estado e do capital estrangeiro, foram publicados em fevereiro de 1949 no chamado Relatório Abbink, cujas linhas gerais guardariam forte correspondência com o Plano Salte, que contemplava os setores de Saúde, Alimentação, Transportes e Energia, apresentado por Dutra ao Congresso Nacional, em maio de 1948.

No segundo governo de Vargas (1951-1954) foi instalada ainda a Comissão Mista Brasil-Estados Unidos para o Desenvolvimento Econômico (CMBEU), que funcionou sob a orientação direta do ministro da Fazenda, Horácio Lafer, entre junho de 1951 e dezembro de 1953. A CMBEU também tinha por finalidade estudar os problemas básicos da economia brasileira e sugerir projetos para o desenvolvimento do país nos diversos setores, tendo-se destacado, dentre suas principais contribuições, a proposta de criação de um banco estatal de investimentos, que esteve na origem da criação do BNDE, em 1952.

A seção brasileira da CMBEU foi chefiada por Ari Frederico Torres, que se tornaria o primeiro presidente do BNDE (1952-1953), e era integrada pelos técnicos Roberto de Oliveira Campos $^{9}$ (Assuntos Econômicos), Glycon de Paiva Teixeira (Assuntos de Geologia e Mineração) e Valentim Bouças (Assuntos Financeiros) - ambos ex-integrantes da Missão Abbink -, além de Lucas Lopes (Questões Técnicas). O relatório final, redigido por Roberto Campos, Glycon de Paiva, Paulo de Assis Ribeiro e o Coronel Mário Poppe de Figueiredo, ligado à Escola Superior de Guerra, foi apresentado em novembro de 1954, já no governo de Café Filho (1954-1955). Retomando estudos realizados pelas missões anteriores, a CMBEU preparou cerca de 40 projetos nas áreas de infra-estrutura e indústrias de base, a serem financia- 
dos com investimentos do Banco Mundial e do Eximbank e aportes internos administrados pelo BNDE, os quais seriam em grande medida incorporados ao Programa de Metas de Juscelino Kubitschek (1956-1961).

Ainda no segundo governo de Vargas, em fevereiro de 1951, foi criada a assessoria econômica da presidência da República, chefiada por Rômulo Almeida, ex-membro da Missão Abbink e economista ligado à Confederação Nacional da Indústria, mais tarde integrante da equipe do Programa de Metas, e depois por outro técnico nacionalista, Jesus Soares Pereira, antigo funcionário do Ministério da Agricultura. A assessoria foi responsável pela elaboração dos projetos de lei do Plano do Carvão Nacional, da criação da Petrobrás, em 1951, e da Eletrobrás, em 1954.

A partir do governo de Juscelino Kubitschek, a ampliação da participação do governo federal realizou-se por intermédio do aparato institucional da chamada administração paralela, materializada nas novas agências conselhos e grupos executivos - organizadas na esfera da presidência da República e no Ministério da Fazenda. O núcleo básico do Programa de Metas era formado pelo Conselho do Desenvolvimento e pelo BNDE.

O Conselho do Desenvolvimento foi criado pelo Decreto n. 38.744, de $1^{\circ}$ de fevereiro de 1956, e era composto por todos os ministros de Estado, pelos chefes dos Gabinetes Civil e Militar e pelos presidentes do Banco do Brasil e do BNDE, tendo como função principal realizar o exame e a aprovação dos incentivos previstos para os diversos projetos incluídos no Programa de Metas, que retomavam em grande medida o relatório final da CMBEU bem como os estudos contidos no Esboço de um programa de desenvolvimento para a economia brasileira - período de 1955-1962, do Grupo Misto de Estudos BNDE-Cepal.

O Conselho do Desenvolvimento funcionou através de grupos de trabalho e grupos executivos, que se compunham de representantes dos órgãos responsáveis pela concessão dos diversos incentivos. Inicialmente eram constituídos os grupos de trabalho, que variavam de tamanho, cada um com um coordenador, e que podiam deixar de existir tão logo os programas da meta ou subsetor em estudo fossem delineados. Em outros casos, quando era necessário que exercessem funções normativas, os grupos de trabalho podiam ser transformados em grupos executivos, sendo essa estrutura, bastante informal, adequada à composição e à redução do conflito potencial entre as diversas agências envolvidas, com vistas à acomodação dos interesses dos respectivos grupos, garantindo-se o alinhamento entre as decisões empresariais e as do governo. Além disso, por se situarem fora do âmbito do Congresso Nacional, os membros dos grupos de trabalho e 
dos grupos executivos tornavam-se mais diretamente responsáveis pelas decisões no seu campo de atuação, uma vez que suas propostas não sofriam os constrangimentos a que estavam submetidas as medidas legislativas (LAFER, 2002).

A secretaria geral do Conselho do Desenvolvimento, órgão de coordenação executiva mais importante, era constituída pela incorporação de servidores civis e militares e técnicos requisitados de autarquias e empresas de economia mista, além de órgãos como o próprio BNDE, a Carteira de Crédito Exterior do Banco do Brasil (Cacex) e a Superintendência da Moeda e do Crédito (Sumoc). O órgão contou ainda com uma ampla participação de pessoal contratado, como os consultores especiais, oriundos em sua maioria de experiências anteriores de planejamento, sobretudo na Missão Abbink, na CMBEU e na antiga assessoria econômica de Vargas. Os principais responsáveis pela condução do Programa de Metas foram Lucas Lopes e Roberto Campos, antigos membros da CMBEU, que ocuparam sucessivamente o cargo de secretário-geral do Conselho, em ambos os casos, acumulando também a presidência do BNDE.

\section{CONSIDERAÇÕES FINAIS}

Foram notadas algumas similitudes entre o segundo governo de Vargas e o de Juscelino Kubistchek nas iniciativas referentes à criação dos órgãos destinados a fomentar a industrialização acelerada, tendo sido o mesmo processo acompanhado, em ambos os casos, pelo recurso às retóricas nacionalistas. Teve destaque, no período de Juscelino, a sofisticada reflexão elaborada no âmbito do debate nacionalista promovido no Instituto Superior de Estudos Brasileiros (FICO, 2000, p. 178).

O que pretendo sustentar, entretanto, é que, para além das correspondências entre esses governos, poderia ser estabelecida uma continuidade para um intervalo mais amplo, abarcando o período desde o advento da industrialização restringida, na década de 1930, quando já se registrava uma forte tendência à concentração do processo decisório da política econômica por setores da burocracia técnica, integrados por engenheiros, economistas e oficiais militares. Essa mesma tendência marcou o processo histórico de formação do Estado capitalista brasileiro, nas correspondentes etapas de nacionalização e especialização, caracterizadas pela ampliação das atividades exercidas pela mesma burocracia.

Somente adotando essa perspectiva mais ampla, que garante a valorização do caráter crescentemente político da participação dos técnicos, 
poder-se-ia avançar uma interpretação sobre a adesão de alguns desses quadros às articulações promovidas por agências como a Consultec, o Instituto de Pesquisas e Estudos Sociais (Ipes) e o Instituto Brasileiro de Ação Democrática (Ibade), para a deposição do presidente João Goulart (1961-1964), apontada em caráter pioneiro por René Armand Dreifuss (1981).

No mesmo contexto, temas caros ao discurso produzido nesses setores, como a defesa reiterada da supremacia da técnica sobre a politica e a desvalorização da política, em sentido estrito - atividade associada à atuação partidária e parlamentar -, guardavam forte correspondência com alguns dos argumentos centrais da geopolítica da Escola Superior de Guerra e da doutrina de segurança nacional, concorrendo para a elaboração da ideologia autoritária, que justificou a ruptura institucional de 1964 e a consolidação do novo regime.

Aperfeiçoada desde a experiência da participação das missões de colaboração brasileiro-americanas, na década de 1940, a consciência dos técnicos sobre os problemas nacionais levaria ainda à consideração da questão do imperialismo e do capital estrangeiro, concorrendo igualmente para sua adesão ao projeto de aprofundamento da internacionalização da economia brasileira, implementado na segunda metade da década de 1960.

Notes ON CAPITALIST STATE-BUILdING IN BRAZIL: NATIONALIZATION AND SPECIALIZATION (1930-1964)

ABSTRACT: This article proposes a contribution to the investigation on both historical process of capitalism development, and state-building in Brazil, based on an analysis of institutional settings and the composition of some branches of Brazilian technical bureaucracy, from Getulio Vargas first term of office (1930-1945), to 1964, by the advent of the military regime. This study aims to debate the interpretation of Brazilian historiography proposed by the Authoritarian Modernization theory, in order to investigate the role of the technical bureaucracy inside the public agencies.

KEY wORDS: Capitalism development, State-building, Bureaucracies.

\section{NOTAS}

1 Sigo como referência o esquema proposto por Charles Tilly para a análise do longo processo de formação dos Estados nacionais europeus na época moderna, dizendo respeito ao avanço do governo direto sobre as duas atividades principais de tributação (extração do capital) e burocratização dos exércitos (controle da coerção), nas etapas de patrimonialismo, corretagem, nacionalização e especialização (Tilly, 1996, p. 78-84). A utilização do mesmo esquema, como referência para análises comparativas e na abordagem do processo de formação dos 
Estados nacionais do Terceiro Mundo, é sugerida pelo mesmo autor (Tilly, 1996, p. 279-315). Na formação do Estado brasileiro, poder-se-ia considerar o arranque da etapa de nacionalização no impulso à criação do exército nacional, desde a experiência da Guerra do Paraguai (1864-1870), a que se segue o advento da República, passando pelas iniciativas de profissionalização das forças armadas, ao longo do século XX. À etapa da especialização corresponderia o processo de expansão do Estado, iniciado na República Velha, com a politização da economia, e acelerado no pós-1930, com a rápida multiplicação de iniciativas de políticas públicas e formação de agências governamentais.

2 Esse entendimento baseia-se no conceito de Estado desenvolvido por Nicos Poulantzas, o qual não deve ser considerado como uma entidade "intrínseca", mas "como uma relação, mais exatamente como a condensação material de uma relação de forças entre classes e frações de classe, tal como ela se expressa, de maneira sempre específica, no seio do Estado" (PoulantZas, 1985, p. 147).

3 A hipótese da estagnação das economias latino-americanas contida na análise de Tavares foi corroborada na mesma época por Celso Furtado, no ensaio intitulado Subdesenvolvimento e estagnação na América Latina (1965), devendo ser lembrado que ambas as contribuiçöes, de Tavares e Furtado, foram elaboradas no contexto de crise das economias latino-americanas, cujas causas foram atribuídas naquele momento ao esgotamento do modelo de industrialização por substituição de importações (GREMAUD et al., 1997, p. 112114). No mesmo contexto, o programa estruturalista seria associado ao conjunto de reformas visando melhorar a distribuição de renda e dinamizar os mercados internos, que antecipou a reação conservadora e autoritária que atingiu o Brasil e outros países da América Latina a partir de meados dos anos 60 . O novo quadro político determinou em alguns setores do campo intelectual, ligados à esquerda e aos nacionalismos, um aprofundamento do pessimismo com relação às perspectivas e à viabilidade dos projetos de industrialização e modernização, quando não do próprio desenvolvimento capitalista nas regiões atrasadas e periféricas do sistema econômico mundial (FIORI, 1999, p. 28), que, entretanto, tiveram continuidade, com os regimes militares que se implantavam no continente, na opção decisiva pela internacionalização.

4 Entre outras contribuições que se aproximaram da nova perspectiva de análise da história do capitalismo brasileiro, destacam-se A inflação brasileira (1963), de Inácio Rangel, A economia da dependência imperfeita (1977) e A economia brasileira: crítica à razão dualista (1972), de Francisco de Oliveira, Desenvolvimento e crise (1968), de Paul Singer, que resumiram o cerne do debate sobre o desenvolvimento industrial no Brasil e a nova proposta de periodização da história do capitalismo brasileiro.

5 Essa nova formulação teórica teria contribuído para a crítica da política econômica do regime militar e para a formulação de um projeto de reforma do desenvolvimentismo brasileiro, o qual conduziria a algumas das medidas de

História Revista, Goiânia, v. 13, n. 1, p. 21-44, jan./jun. 2008 
política econômica do período de transição democrática no Brasil, entre 1985 e 1988 (FIORI, 1999, p. 35).

6 Para uma revisão sobre o conceito de populismo e da periodização proposta nessa vertente, ver Gomes (1996).

7 Carlos Lessa e José Luís Fiori ressaltaram as limitações da concepção varguista e recusaram o caráter "premonitório" que teria sido sugerido para esse projeto na interpretação de Draibe. Segundo esses autores, mais do que um conjunto integrado de iniciativas com vistas à promoção rápida da industrialização, teria se destacado no período a ênfase mais estrita na remoção das insuficiências infra-estruturais que inibiam o crescimento industrial (LESSA e FIORI, 1983, p. 10 e 26).

8 O economista Otávio Gouveia de Bulhões integrou diversos grupos de trabalho no Conselho do Desenvolvimento e foi Ministro da Fazenda do governo de Castelo Branco (1964-1967). Glycon de Paiva Teixeira era geólogo do DNPM e tinha participado de comissōes ligadas à política mineral, tornando-se, em 1955, diretor da Companhia Vale do Rio Doce. O empresário Valentim Bouças especializou-se, como autodidata, em assuntos economicos, foi secretáriotécnico do Conselho Técnico de Economia e Finanças, do Estado Novo, e fundou a revista O Observador Econômico Financeiro. Com Roberto Campos e Otávio Gouveia de Bulhões, participou da delegação brasileira à Conferência Monetário-Financeira da Organização das Nações Unidas (ONU) em Bretton Woods (EUA), em 1944. Rômulo Barreto de Almeida chefiou a assessoria econômica da presidência da República no segundo governo de Getúlio Vargas (1951-1954). O engenheiro gaúcho Ari Frederico Torres havia sido diretor do Instituto de Pesquisas Tecnológicas de São Paulo (ABreu et al., 2001). Villela, Annibal Vilanova; Suzigan, Wilson. Política de governo e crescimento da economia brasileira. Rio de Janeiro: IPEA, 1975. WEFForT, Francisco. Por que democracia? São Paulo: Brasiliense, 1984. WIRTH, John. A política do desenvolvimento na era Vargas. Rio de Janeiro: Fundação Getúlio Vargas, 1973.

9 O economista Roberto de Oliveira Campos, diplomata de carreira, integrou a CMBEU em 1951 e, no ano seguinte, tornou-se diretor econômico do BNDE. Presidiu o Conselho do Desenvolvimento (1958-1959) e no governo de Castelo Branco (1964-1967) assumiu o Ministério Extraordinário para o Planejamento e Coordenação Econômica, quando, juntamente com Otávio Gouveia de Bulhões, tornou-se responsável pelas principais diretrizes econômicas do governo (CAMPOS, 1994, v. 1. p. 159-164; 196-197).

\section{REFERÊNCIAS}

Abreu, Alzira Alves de et al. (Org.). Dicionário histórico-biográfico brasileiro pós1930. 2. ed. Rio de Janeiro: Ed. FGV, 2001. (CD-ROM).

Maria Letícia Corrêa. Notas sobre a formação do Estado capitalista no Brasil:... 
ABReu, Marcelo de Paiva (Org.). A ordem do progresso: cem anos de política econômica republicana 1889-1989. Rio de Janeiro: Campus, 1989.

ANDERSON, Perry. Linhagens do estado absolutista. São Paulo: Brasiliense, [1974] 1985.

BIELSCHOWSKI, Ricardo Alberto. Pensamento econômico brasileiro: o ciclo ideológico do desenvolvimentismo. Rio de Janeiro: Contraponto, 1995.

CAmpos, Roberto. A lanterna na popa: memórias. Rio de Janeiro: Topbooks, 1994.2 v.

CARDoso, Fernando Henrique. Autoritarismo e democratização. Rio de Janeiro: Paz e Terra, 1975.

DEAN, Warren. A industrialização de São Paulo. São Paulo: Difel, 1971.

DiAs, José Luciano de Mattos. Os engenheiros do Brasil. In: Gomes, Ângela de Castro (Org.). Engenheiros e economistas: novas elites burocráticas. Rio de Janeiro: Ed. FGV, 1994.

DinIz, Eli. Empresariado, estado e capitalismo no Brasil: 1930-1945. Rio de Janeiro: Paz e Terra, 1978.

DiNIZ, Eli. Engenharia institucional e políticas públicas: dos conselhos técnicos às câmaras setoriais. In: PANDolfi, Dulce (Org.). Repensando o Estado Novo. Rio de Janeiro: Ed. FGV, 1999.

DraIBE, Sônia. Rumos e metamorfoses: um estudo sobre a constituição do Estado e as alternativas da industrialização no Brasil, 1930-1960. Rio de Janeiro: Paz e Terra, 1985.

DreIfuss, René Armand. 1964: a conquista do estado - ação política, poder e golpe de classe. Rio de Janeiro: Vozes, 1981. p. 104.

FERNANDES, Florestan. A revolução burguesa no Brasil: ensaio de interpretação sociológica. Rio de Janeiro: Zahar, 1975.

Fico, Carlos. O Brasil no contexto da Guerra Fria: democracia, subdesenvolvimento e ideologia. In: MoTA, Carlos Guilherme (Org.). Viagem incompleta. A experiência brasileira (1500-2000): a grande transação. 2. ed. São Paulo: Senac, São Paulo, 2000.

FIORI, José Luís. De volta à questão da riqueza de algumas naçōes. In: (Org.). Estados e moedas no desenvolvimento das nações. Petrópolis: Vozes, 1999.

FurTado, Celso. Formação econômica do Brasil. Rio de Janeiro: Fundo de Cultura, 1959.

1965.

Desenvolvimento e subdesenvolvimento. Rio de Janeiro: Fundo de Cultura,

GERSCHENKRON, Alexander. Economic backwardness in historical perspective: a book of essays. Cambridge, MA: Belknap Press of Harvard University Press, 1962.

História Revista, Goiânia, v. 13, n. 1, p. 21-44, jan./jun. 2008 
Gomes, Ângela de Castro. O populismo e as ciências sociais no Brasil: notas sobre a trajetória de um conceito. Tempo. Niterói, v. 1, n. 2, p. 31-58, 1996.

Gremaud, Amaury Patrick et al. Formação econômica do Brasil. São Paulo: Atlas, 1997.

JaGuaribe, H. et. al. Brasil: sociedade democrática. Rio de Janeiro: José Olympio, 1985.

LAFER, Celso. JK e o programa de metas (1956-1961): processo de planejamento e sistema político no Brasil. Rio de Janeiro: Ed. FGV, 2002.

Lessa, Carlos; FIori, José Luís. Relendo a política econômica: as falácias do nacionalismo popular do segundo Vargas. Rio de Janeiro: UFRJ/IEI, 1983.

Martins, Luciano. Pouvoir et developpement economique: formation et evolution des structures politiques au Brésil. Paris: Anthropos, 1976.

MAZA, Fábio. O idealismo prático de Roberto Simonsen: ciência, tecnologia e indústria na construção da Nação. São Paulo: Instituto Roberto Simonsen, 2004.

Mello, João Manuel Cardoso de. O capitalismo tardio. São Paulo: Brasiliense, 1982.

MEndonçA, Sonia Regina de. Estado e economia no Brasil: opções de desenvolvimento. Rio de Janeiro: Graal, 1985.

Ruralismo: agricultura, poder e Estado na Primeira República. 1990. Doutorado (Tese) - FFLCH, Universidade de São Paulo, São Paulo: 1990.

MoORe JR., Barrington. As origens sociais da ditadura e da democracia: senhores e camponeses na construção do mundo moderno. São Paulo: Martins Fontes, [1962]1983.

Oliveira, Francisco de. A economia da dependência imperfeita. Rio de Janeiro: Graal, 1977.

Oliveira, Francisco de. Crítica à razão dualista: o ornitorrinco. São Paulo: Boitempo, [1972]2003.

PeLAEZ, Manuel Carlos. História da industrialização brasileira. Rio de Janeiro: APEC, 1972.

Poulantzas, Nicos. O Estado, o poder e o socialismo. Rio de Janeiro: Graal, 1985.

PREBISCH, Raul. El desarrollo económico de América Latina y algunos de sus principales problemas. Santiago (Chile): Cepal, 1949.

RANGel, Inácio. A inflação brasileira. Rio de Janeiro: Tempo Brasileiro, 1963.

SiMONSEN, Roberto C. A evoluçâo industrial do Brasil e outros estudos. Rio de Janeiro: Cia. Editora Nacional, [1939]1972.

SINGER, Paul. Desenvolvimento e crise (1968). São Paulo: Difel, 1968.

SolA, Lourdes. Estado, mercado, democracia política e economia comparada. São Paulo: Paz e Terra, 1993.

Maria Letícia Corrêa. Notas sobre a formação do Estado capitalista no Brasil:... 
Idéias econômicas, decisões políticas: desenvolvimento, estabilidades e populismo. São Paulo: Edusp/Fapesp, 1998.

TAVAres, Maria da Conceição. Acumulação de capital e industrialização no Brasil. Campinas: Ed. Unicamp, 1974.

TAVARES, Maria da Conceição; SERRA, J. Mais além da estagnação (1970). In: TAVArES, Maria da Conceição. Da substituição de importações ao capitalismo financeiro. Rio de Janeiro: Zahar, [1963]1972.

Tilly, Charles. Coerção, capital e Estados europeus. São Paulo: Edusp, 1996.

Villela, Annibal Vilanova; Suzigan, Wilson. Políticas de governo e crescimento da economia brasileira. Rio de Janeiro: IPEA, 1975.

Weffort, Francisco. Por que democracia? São Paulo: Brasiliense, 1984.

WIRTH, John. A política do desenvolvimento na era Vargas. Rio de Janeiro: Fundação Getúlio Vargas, 1973.

História Revista, Goiânia, v. 13, n. 1, p. 21-44, jan./jun. 2008 